\title{
Effects of low and high dose intraarticular tiludronate on synovial fluid and clinical variables in healthy horses - a preliminary investigation
}

To determine effects of intraarticularly administered tiludronate on articular cartilage in vivo, eight healthy horses were injected once with tiludronate (low dose tiludronate [LDT] 0.017 $\mathrm{mg}, \mathrm{n}=4$; high dose tiludronate [HDT] $50 \mathrm{mg}, \mathrm{n=4}$ ) into one middle carpal joint and with saline into the contralateral joint. Arthrocentesis of both middle carpal joints was performed pretreatment, and 10 min, 24 h, 48 h, 7 and 14 days after treatment. Synovial nucleated cell counts and total solids, tiludronate, sulfated glycosaminoglycan (sGAG), chondroitin sulfate 846 epitope (CS-846, a measure of aggrecan synthesis), and collagen type II cleavage neoepitope (C2C) concentrations were determined. Histologic analysis of joint tissues and sGAG quantitation in cartilage was performed at 14 days in HDT horses. Data were analyzed by repeated measures non-parametric ANOVA and Wilcoxon signed-rank test. High dose tiludronate administration produced synovial fluid tiludronate concentrations of $2,677,500$ $\mathrm{ng} / \mathrm{mL}$, exceeding concentrations that were safe for cartilage in vitro, and LDT administration produced synovial fluid concentrations of $1,353 \mathrm{ng} / \mathrm{mL}$, remaining below concentrations considered potentially detrimental to cartilage. With HDT, synovial fluid total solids concentration was higher at $24 \mathrm{~h}$ and 7 days and sGAG concentration was higher at $48 \mathrm{~h}$, compared to control joints. Synovial fluid CS-846 concentration was increased over pretreatment values in HDT control but not in HDT treated joints at 24 and $48 \mathrm{~h}$. All joints (HDT and LDT control and treated) showed a temporary decrease in synovial fluid C2C concentration, compared to pre-treatment values. Histologic features of articular cartilage and synovial membrane did not differ between HDT treated and control joints. High dose tiludronate treatment caused a transient increase in synovial total solids and temporarily 
increased proteoglycan degradation in cartilage. Although clinical significance of these changes are questionable, as they did not result in articular cartilage damage, further investigation of the safety of intraarticular HDT in a larger number of horses is warranted. 
1 Katja F. Duesterdieck-Zellmer ${ }^{1}$, Lindsey Moneta ${ }^{2}$, Jesse F. Ott ${ }^{1}$, Maureen K. Larson ${ }^{1}$, Elena M.

2 Gorman $^{3}$, Barbara Hunter ${ }^{1}$, Christiane V. Löhr ${ }^{3}$, Mark E. Payton ${ }^{4}$, Jeffrey T. Morré ${ }^{5}$, Claudia S.

3 Maier $^{5}$

$4{ }^{1}$ Department of Clinical Sciences, College of Veterinary Medicine, Oregon State University,

5 Corvallis, OR 97331, USA

$6{ }^{2}$ College of Veterinary Medicine, Oregon State University, Corvallis, OR 97331, USA

$7{ }^{3}$ Department of Biomedical Sciences, College of Veterinary Medicine, Oregon State University,

8 Corvallis, OR 97331, USA

$9{ }^{4}$ Department of Statistics, Oklahoma State University, Stillwater, OK 74078, USA

$10{ }^{5}$ Department of Chemistry, Oregon State University, Corvallis, OR 97331, USA

11 Corresponding author: K.F. Duesterdieck-Zellmer, Department of Clinical Sciences, College of

12 Veterinary Medicine, Oregon State University, Corvallis, OR 97331, USA, phone: +1-541-737-

13 8399, E-mail address: katja.zellmer@oregonstate.edu. 


\section{Introduction}

15 Tiludronate, a non-nitrogen containing bisphosphonate, slows bone turnover by causing 16 apoptosis in osteoclasts (Rogers et al., 2011). This effect may be useful to treat conditions

17 associated with an increase in bone turnover, such as navicular disease or osteoarthritis. In fact,

18 some horses with navicular disease (Denoix, Thibaud \& Riccio, 2003), osteoarthritis of the distal 19 tarsal joints (Gough, Thibaud \& Smith, 2010) or the thoracolumbar facet joints (Coudry et al., 20 2007) exhibited decreased signs of pain associated with their condition after systemic tiludronate 21 treatment. In humans, atypical subtrochanteric and femoral shaft fractures have been reported 22 after years of treatment (Nieves \& Cosman, 2010). In horses, only anecdotal reports of side 23 effects are available to date, which have included colic, tachycardia, electrolyte imbalances, and 24 presumed association with renal failure. Concerns regarding side effects and the high cost of 25 systemic treatment constitute possible reasons why veterinarians have begun to administer 26 tiludronate locally via intraarticular injection or regional limb perfusion. However, no 27 information is available concerning safety, efficacy, or appropriate doses of these routes of 28 administration. Based on in-vitro results (Duesterdieck-Zellmer, Driscoll \& Ott, 2012), the extra-

29 label use of tiludronate via intraarticular injection or regional limb perfusion, especially in high 30 doses, may result in deleterious effects for articular cartilage. While it is common belief among

31 veterinarians who have been using this drug in an extra-label fashion, that no untoward effects

32 exist, this view is scientifically unfounded. Further, lameness after treatment is likely being 33 attributed to the cause for the original lameness problem and not to negative effects of

34 tiludronate. Thus, it is imperative to investigate possible deleterious effects of extra-label routes 35 of administration for tiludronate in horses.

36 Little is known about tiludronate's effects on joint tissues after intraarticular 37 administration. Concentration-dependent effects of tiludronate on articular cartilage in-vitro 
38 (Duesterdieck-Zellmer, Driscoll \& Ott, 2012) raise concerns about the safety of higher doses

39 administered intraarticularly. More specifically, tiludronate concentrations of $\geq 19,000 \mathrm{ng} / \mathrm{mL}$

40 increased chondrocyte apoptosis and release of glycosaminoglycans from equine articular

41 cartilage explants, suggesting that doses resulting in synovial fluid concentrations of $\geq 19,000$

$42 \mathrm{ng} / \mathrm{mL}$ may promote articular cartilage damage (Duesterdieck-Zellmer, Driscoll \& Ott, 2012).

43 Anecdotally, the intraarticular dose of tiludronate is $50 \mathrm{mg}$ per joint, which is likely to result in

44 synovial fluid concentrations above $19,000 \mathrm{ng} / \mathrm{mL}$ when injected into the middle carpal joint,

45 based on an estimated synovial fluid volume of $15 \mathrm{~mL}$ for this joint (Ekman et al., 1981). This

46 dose was chosen as the high dose in this study, whereas the low dose $(0.017 \mathrm{mg}$ of tiludronate per

47 joint) was chosen to result in synovial fluid concentrations of about $1,900 \mathrm{ng} / \mathrm{mL}$. The objective

48 of this study was to determine effects of low dose tiludronate (LDT) and high dose tiludronate

49 (HDT) administered intraarticularly to healthy horses. We hypothesized that a single intraarticular

50 injection of HDT, but not of LDT would have a negative impact on clinical, clinicopathologic,

51 and biochemical indicators of joint health, compared to observations in contralateral control

52 joints injected with the same volume of saline. We further hypothesized that these negative

53 effects would result in histologically detectable articular cartilage damage in joints administered

54 HDT.

\section{Materials and methods}

56 Animals

57 After approval from the Institutional Animal Care and Use Committee, four horses (age

58 12-15 years, two Thoroughbreds, one Warmblood, one Quarter Horse) were enrolled to receive

59 LDT (ACUP 4034, approved 6/29/10) and a year later, four different horses (age 2-18 years,

60 Quarter Horses) were enrolled to receive HDT. All horses were without front limb lameness and 
61 radiographic abnormalities of their carpal joints. They were housed in box stalls and offered free

62 choice grass hay and water during experiments.

\section{Study Design}

64 Baseline lameness examinations were conducted, followed by sedation with detomidine

65 (Dormosedan, Pfizer) and butorphanol (Torbugesic, Fort Dodge; both $0.01 \mathrm{mg} / \mathrm{kg}$ IV) for

66 arthrocentesis of both middle carpal joints (performed by KDZ and LM). After withdrawing up to

$672 \mathrm{~mL}$ joint fluid (used to determine all synovial fluid variables as described below), $0.017 \mathrm{mg}$

68 tiludronate (Tildren, Ceva) in $1 \mathrm{~mL}$ saline was injected into one randomly assigned middle carpal

69 joint of four horses, and $1 \mathrm{~mL}$ saline was injected into the contralateral middle carpal joint (year

70 one, LDT). The other four horses (year two, HDT) were treated similarly, using an intraarticular

71 dose of tiludronate of $50 \mathrm{mg}$ in $6 \mathrm{~mL}$ saline as treatment and $6 \mathrm{~mL}$ saline as control.

72 Randomization was performed via coin toss for each horse and investigators were blinded to

73 treatment allocation by an assistant removing the label from the syringes before injection. Both

74 joints were flexed and extended manually 15 times after injection. Aspiration of $0.5 \mathrm{~mL}$ joint

75 fluid (used purely for determination of tiludronate concentrations) was performed after $10 \mathrm{~min}$ on

76 both middle carpal joints. This resulted in removal of an estimated reduction of the effective

77 intraarticular dose of tiludronate by $3 \%$ for LDT and $2.5 \%$ for HDT based on a presumed

78 synovial fluid volume of $15 \mathrm{~mL}$ in the middle carpal joints (Ekman et al., 1981) and the

79 assumption that none of the saline used as diluent for tiludronate had been absorbed from the

80 joint space by 10 min post treatment. Repeat arthrocenteses of up to $3 \mathrm{~mL}$ joint fluid were

81 performed after 24 and 48 h, 7 and 14 days (used for determination of all synovial fluid variables

82 as described below). All horses treated with HDT were euthanatized on day 14 (Beuthanasia,

83 Merck; $1 \mathrm{~mL} / 4.54 \mathrm{~kg} \mathrm{IV}$ ) and articular cartilage from the radial facet of both third carpal bones 
84 and adjacent synovial membrane were collected. Investigators were blinded to treatment

85 allocations for all sample analyses.

\section{Clinical variables}

87 Horses underwent daily physical and lameness examinations (performed by KDZ and

88 LM), including palpation of both carpi for pain, effusion (none, mild, moderate, severe) and

89 development of edema, measurement of joint circumference of the middle carpal joints at the

90 level of a clipped mark on the lateral aspect of each middle carpal joint, and measurement of the

91 angle of maximum flexion of both carpi (Baseline Plastic Goniometer, Fabrication Enterprises).

92 For the latter, the angle present on the caudal/palmar aspect of the limb was measured. Thus, an

93 increase in angle of maximum flexion would indicate decreased range of motion of the carpal

94 joints. Horses were observed walking and trotting in a straight line, and trotting after flexion of

95 both carpi for $1 \mathrm{~min}$. Lameness was categorized as sound, intermittently lame at the walk or trot,

96 consistently lame at the trot, or consistently lame at the walk. Responses to carpal flexion tests

97 were graded as positive when obvious lameness persisted for more than four strides (Ross, 2011).

98 Synovial fluid analyses

99 Synovial fluid samples were divided into $0.3 \mathrm{ml}$ aliquots, of which one was placed in

100 EDTA containing tubes (Monoject, Covidien) for cytologic analysis. This aliquot was stored at 4

$101{ }^{\circ} \mathrm{C}$ until cytologic analysis within $12 \mathrm{~h}$ of sample collection. All other aliquots were stored at -80

$102{ }^{\circ} \mathrm{C}$ until sample analyses within 6 months of collection. All samples from year one (LDT) were

103 analyzed as one batch, and all samples from year two (HDT) were analyzed as one separate

104 batch. 
106 Bellingham+Stanley). Total nucleated cell count was determined manually (Leuko-Tic,

107 Bioanalytic). Differential cell counts were obtained manually on Wright's-Giemsa stained

108 cytocentrifuge-prepared slides (CytoSpin* 4 Cytocentrifuge, Thermo Scientific).

109 Synovial fluid sulfated glycosaminoglycan (sGAG) concentration was determined

110 employing the 1,9-dimethylmethylene blue (DMMB) assay as described (Oke et al., 2003), with

111 some modifications. Briefly, samples were added to equal volumes of papain digestion buffer (2

$112 \mathrm{mg} / \mathrm{mL}$ papain) and mixed at $65^{\circ} \mathrm{C}$ for $3 \mathrm{~h}$, followed by an additional 1:3 (v:v) dilution in papain 113 digestion buffer. Each sample was placed in triplicates into wells ( $5 \mu \mathrm{L} /$ well) of a 96 well plate

114 (nunc Optical Bottom Plate non-treated, Thermo Scientific). Immediately before measurement of 115 absorbance at $540 \mathrm{~nm}, 245 \mu \mathrm{L}$ of DMMB working solution $(0.016 \mathrm{mg} / \mathrm{mL}$ DMMB $)$ was added to 116 each appropriate well using a multichannel pipette. Sample concentrations were calculated from a 117 standard curve of chondroitin-6-sulfate $(31.25-500 \mu \mathrm{g} / \mathrm{mL}$; Chondroitin 6-sulfate from shark 118 cartilage, Sigma Aldrich).

121 manufacturer's instructions. Briefly, synovial fluid samples were centrifuged (16,000 x g for 2

$122 \mathrm{~min}$ ) and diluted 1:60 in Buffer III (provided by the manufacturer) and run in duplicates. A color

123 change was measured at 450nm (Multiskan Go, Thermo Scientific) and sample concentrations

124 were calculated from a standard curve of $20-1000 \mathrm{ng} / \mathrm{mL} \mathrm{CS}-846$. 
126 neoepitope (C2C) in synovial fluid via ELISA (IBEX Technologies) according to manufacturer's

127 instructions. Briefly, synovial fluid samples were centrifuged (16,000 x g for $2 \mathrm{~min})$ and diluted

128 1:2 in Buffer III (provided by the manufacturer) were run in duplicates. A color change was

129 measured at 450nm (Multiskan Go, Thermo Scientific). Sample concentrations were calculated

130 from a standard curve of $10-1000 \mathrm{ng} / \mathrm{mL} \mathrm{C} 2 \mathrm{C}$.

131 Tiludronate concentration was determined by high performance liquid chromatography

132 (XBridge phenyl column, Waters) followed by mass spectrometry (Tarcomnicu et al., 2009; Zhu

133 et al., 2006). Tiludronate was methylated using $0.2 \mathrm{M}$ trimethylsilyldiazomethane in acetone.

134 Sample concentrations were calculated from a standard curve of $0.5-64 \mathrm{ng} / \mathrm{mL}$ tiludronate.

135 Samples with tiludronate concentrations above the range of the standard curve were serial diluted 136 to fall within that range. Positive and negative control samples were run with each batch of 137 samples and deuterated tiludronate (Toronto Research Chemicals) was used as internal control in 138 each sample. The lower level of detection for this assay was $10 \mathrm{ng} / \mathrm{mL}$.

139 Joint tissue analyses ( $\mathrm{n}=4$, HDT)

140 Cartilage samples from the radial facet of both $3^{\text {rd }}$ carpal bones were digested with papain

141 ( $1 \mathrm{~mL}$ papain digestion buffer as described above per $10 \mathrm{mg}$ cartilage wet weight) for $\geq 24 \mathrm{~h}$ until 142 no particulate matter was visible in the sample. Subsequently, sGAG content was determined via 143 DMMB assay as described above.

144 Histologic analysis on paraffin embedded sections of cartilage and synovial membrane 145 was performed by a board-certified veterinary pathologist (CVL) who was unaware of treatment 146 allocations. Hematoxylin and eosin stained cartilage sections were graded on a scale of 0-4 for 
147 chondrocyte necrosis, chondrocyte clusters, cartilage fibrillation or fissures, and focal cell loss

148 (McIlwraith et al., 2010). Cartilage sections stained with toluidine blue (for proteoglycans) were

149 graded on a scale of 0-4 for loss of staining (McIlwraith et al., 2010). Hematoxylin and eosin

150 stained synovial membrane sections were graded on a scale of 0-4 for cellular infiltration with

151 lymphocytes and plasma cells, and intimal hyperplasia (McIlwraith et al., 2010). Scores were

152 recorded for three independent readings and the median score was determined.

153 Chondrocyte apoptosis was assessed on cartilage sections using the terminal

154 deoxynucleotidyl transferase dUTP nick end labeling (TUNEL) method (In Situ Cell Death

155 Detection Kit, AP, Roche) as described previously (Duesterdieck-Zellmer, Driscoll \& Ott, 2012).

\section{Data Analysis}

Data were expressed as median and total range, other than tiludronate concentrations,

158 which were expressed as mean and standard error of the mean. To assess possible negative effects

159 of intraarticular administration of LDT or HDT on normal joints, differences between treated and

160 control joints within the same horse were determined using a two factor factorial model (dose of

161 tiludronate and treatment with saline or tiludronate) with repeated measures via non-parametric

162 ANOVA. To assess effects of LDT or HDT on normal joints over time, differences between

163 measurements prior to experimental treatment (baseline) and time points after experimental

164 treatment within the same joints (LDT control joints, LDT treated joints, HDT control joints, or

165 HDT treated joints) were determined. Comparisons between joints treated with HDT and joints

166 treated with LDT were not performed, as experiments were conducted in two different years and

167 samples were analyzed in different batches. Further, this comparison is of lower importance, as

168 the study did not aim at determining which dose was safer than the other. For variables in which

169 the main effect of time was not significant, median values for each treatment group (LDT control 
170 joints, LDT treated joints, HDT control joints, HDT treated joints) were calculated by pooling all

171 time points. For those variables in which time significantly influenced the outcome, medians

172 were calculated for each time point separately. Data from post-mortem analyses in horses treated

173 with HDT was analyzed using the Wilcoxon signed-rank test. Statistical significance was set at

$174 P=0.05$.

175 A power analysis performed prior to the experiments estimated an $80 \%$ chance of detecting a

176 difference of $30 \%$ between treated and control joints within the same horse with a sample size of $177 \mathrm{n}=4$ and $P<0.05$.

\section{Results}

179 All physical examination variables remained within normal limits in all horses. No pain or 180 edema was evident upon palpation of any carpi, and no lameness or positive response to carpal 181 flexion was noted after tiludronate administration at any time. Mild to moderate effusion of the 182 middle carpal joints was common 1-3 days and 8 days after intraarticular injection of saline, LDT 183 and HDT (Table 1). Joints treated with HDT showed a greater degree of effusion than their saline 184 controls 1 day $(P=0.0162), 3$ days $(P=0.0349)$, and 8 days $(P=0.0349)$ after intraarticular 185 injection. In contrast, in the LDT group, joints treated with saline showed a greater degree of 186 effusion on day eight $(P=0.0349)$ than joints treated with LDT. When comparing joint effusion

187 within experimental groups to baseline observations, HDT control joints showed increased 188 effusion 2 days after injection of saline $(P=0.0008)$, whereas HDT treated joints showed 189 increased effusion 2 days $(P=0.0264), 3$ days $(P=0.0264)$ and 8 days $(P=0.0264)$ after treatment.

190 LDT control joints, showed increased joint effusion 1 day $(P=0.0264), 2$ days $(P<0.0001)$ and 8

191 days $(P=0.0008)$ after intraarticular injections, whereas LDT treated joints showed increased joint 192 effusion 1 day $(P=0.0264)$ and 2 days $(P<0.0001)$ after treatment. 
194 joints $(P=0.3735)$ in horses treated with HDT (28.3 [3.8] cm vs. $28.4[2.7] \mathrm{cm}-$ median and 195 range pooled over time) or LDT (29.0 [5.9] cm vs. 28.8 [6.5] cm - median and range pooled over 196 time).

$198(P=0.0135)$ and 13 days $(P=0.0219)$ after treatment. There was no difference between treated and 199 control joints in horses treated with LDT (all $P>0.3266$ ) at any time. Joint angle of maximum 200 flexion was decreased at multiple time points compared to baseline measurements in HDT 201 treated, HDT control, LDT treated, and LDT control joints (Table 2). All differences were $<10^{\circ}$, 202 and are unlikely to be clinically significant (Liljebrink \& Bergh, 2010).

204 detectable in all joints treated with HDT throughout the study, whereas in joints treated with 205 LDT, tiludronate was not detectable after $24 \mathrm{~h}$. Tiludronate was detectable in two HDT control 206 joints $24 \mathrm{~h}$ after treatment, albeit below the lower margin of quantitation for the assay.

207 Tiludronate was not detectable in any other samples from control joints or in any baseline 208 samples.

209 Synovial total nucleated cell count did not differ between treated and control joints in 210 horses treated with HDT or LDT $(P=0.1165)$. Total nucleated cell counts exceeded the reference 211 interval of 0-500 cells/ $\mu \mathrm{L}$ (Mahaffey, 2002) in three HDT treated joints, including one heavily

212 blood contaminated sample, and in one HDT control joint 7 days after treatment. All other values 213 remained within that reference range. When compared to total nucleated cell counts prior to 214 intraarticular injection, cell counts were increased 24 h, 7 days and 14 days (all $P<0.0001)$ after 
215 treatment in HDT treated joints and 24 h, 48 h,7 days and 14 days (all $P<0.0042)$ after treatment

216 in HDT control joints. Total nucleated cell counts in samples from joints treated with LDT

217 decreased 7 days after treatment compared to baseline values $(P=0.0124)$, and no change over

218 time was found for LDT control joints (all $P>0.7$ ).

219 The percentage of neutrophils among nucleated cells in synovial fluid samples remained

220 within the reference interval of $\leq 10 \%$ (Mahaffey, 2002) in the majority of samples (79\%). The

221 remaining samples had $12-68 \%$ neutrophils, which was considered to be within normal limits due

222 to the very low total nucleated cell counts in these samples (Mahaffey, 2002). The percentage of

223 neutrophils among nucleated cells in synovial fluid samples did not differ over time $(P=0.0871)$

224 nor between treated and control joints $(P=0.3386)$ in horses treated with HDT (4.5 [68] \% vs. 5.5

$225[55] \%$ - median and range pooled over time) or LDT (2 [20] \% vs. 5 [25] \% - median and range

226 pooled over time).

227 Total solids concentration in synovial fluid (Fig. 2) was higher in HDT treated joints than

228 HDT control joints but there was no difference between LDT treated and LDT control joints.

229 Compared to baseline values, total solids increased in HDT treated and HDT control joints for the

230 first 2 days. In LDT treated joints, total solids concentration was decreased at the end of the

231 study, compared to baseline values and there was no difference compared to baseline in LDT

232 control joints.

233 Synovial fluid sGAG concentration (Fig. 3) was greater in HDT treated than HDT control

234 joints on day 2 of the study, but there was no difference between LDT treated and LDT control

235 joints. Compared to baseline values, sGAG concentration tended to increase $(P=0.0513)$ and then

236 decreased over time in HDT treated joints, whereas no increase compared to baseline was seen in 
237 the HDT control joints, and instead, values decreased compared to baseline. In LDT treated or

238 control joints, sGAG concentration did not change compared to baseline.

239 Synovial fluid CS-846 concentration (Fig. 4) was lower in HDT treated joints compared

240 to HDT control joints, whereas there were no differences between LDT treated and LDT control

241 joints. In HDT control joints, synovial fluid CS-846 concentration increased and then returned to

242 not different from baseline levels again and this was not seen in HDT treated joints, as there was

243 no change compared to baseline. In LDT treated and LDT control joints, no change in synovial

244 fluid CS-846 concentration compared to baseline was found.

245 Synovial fluid C2C concentration (Fig. 5) was lower in HDT treated than control joints,

246 as well as in LDT treated compared to LDT control joints. All joints, HDT treated and HDT

247 control joints as well as LDT treated and LDT control joints showed a temporary decrease in C2C

248 concentration, compared to baseline values.

249 No significant difference was found between joints treated with HDT and control joints

250 for sGAG content of articular cartilage (308.0 [15.9] $\mu \mathrm{g} / \mathrm{mg}$ vs. 308.6 [46.8] $\mu \mathrm{g} / \mathrm{mg}$ respectively;

$251 P=1.0)$ or $\%$ of apoptotic chondrocytes $(2.2[1.2] \%$ vs. $1.7[0.6] \% ; P=0.5637)$. Histologic scores

252 for joint tissues were not different between joints treated with HDT and control joints (Table 3).

\section{Discussion}

254 The target tissue for tiludronate has traditionally been bone (EMEA, 2001), but

255 tiludronate also exerts direct effects on cartilage and chondrocytes (Duesterdieck-Zellmer,

256 Driscoll \& Ott, 2012; Emonds-Alt, Breliere \& Roncucci, 1985), especially after extra-label local

257 administration via regional limb perfusion or intraarticular injection, since these routes of 
258 administration potentially result in high synovial fluid concentrations. In-vitro data suggests that

259 synovial fluid tiludronate concentrations of $19,000 \mathrm{ng} / \mathrm{mL}$ and above promote chondrocyte

260 apoptosis and release of sGAGs from articular cartilage matrix, whereas concentrations of 1,900

$261 \mathrm{ng} / \mathrm{mL}$ and below may ameliorate sGAG release and chondrocyte apoptosis in equine joints

262 (Duesterdieck-Zellmer, Driscoll \& Ott, 2012). Subsequently, the dose for the LDT group was

263 chosen to produce synovial fluid tiludronate concentrations approximating $1,900 \mathrm{ng} / \mathrm{mL}$. The

264 dose for HDT was selected based on anecdotal reports of clinical use and was suspected to

265 generate synovial fluid tiludronate concentrations exceeding those considered safe for articular

266 cartilage. As suspected, HDT resulted in synovial fluid concentrations much higher than 1,900

$267 \mathrm{ng} / \mathrm{mL}$ for at least $48 \mathrm{~h}$ after intraarticular injection. This was accompanied by increased synovial

268 fluid sGAG concentration, resulting either from increased degradation and/or increased turnover

269 of sGAGs in articular cartilage (de Grauw, van de Lest \& van Weeren, 2009), which would be

270 associated with an increased sGAG synthesis. To estimate synthesis of sGAGs, synovial CS-846

271 concentrations were determined, as this epitope has been used as a biomarker for aggrecan

272 synthesis (McIlwraith, 2005; Poole et al., 1994; Rizkalla et al., 1992). Aggrecan synthesis

273 appeared to remain unchanged in joints treated with HDT compared to measurements prior to

274 treatment. Thus, increased synovial sGAG concentrations in joints treated with HDT in the

275 present study were most likely associated with cartilage matrix degradation and not with an

276 increased turnover of sGAGs. Increased concentration of sGAG in synovial fluid has also been

277 reported due to repeated arthrocentesis in horses (van den Boom et al., 2005). However, it is

278 unlikely that the increase in sGAG concentration $48 \mathrm{~h}$ after intraarticular injection of HDT was

279 caused by repeated arthrocenteses, as sGAG concentration in contralateral control joints that had

280 undergone the same repeat arthrocentesis protocol as the treated joints were significantly lower

281 than in tiludronate treated joints. Further, repeat arthrocentesis caused a more modest increase in

282 synovial fluid sGAG concentration of about $20 \mu \mathrm{g} / \mathrm{mL}$ (van den Boom et al., 2005) compared to 
283 what was found after HDT in this study (increase in synovial fluid concentratin of about 200

$284 \mu \mathrm{g} / \mathrm{mL})$. Nevertheless, sGAG content in articular cartilage was not found to be different between

285 joints treated with HDT and control joints 14 days after treatment, though this may reflect the

286 small number of horses investigated. A power analysis performed prior to the experiments

287 estimated an $80 \%$ chance of detecting a difference of $30 \%$ between treated and control joints

288 within the same horse with a sample size of $\mathrm{n}=4$ and $\mathrm{P}<0.05$. Another explanation for the lack of

289 difference in sGAG content between HDT treated and control joints may be that tiludronate

290 concentration in HDT treated joints remained within a range that has been shown to decrease

291 sGAG release from articular cartilage matrix in vitro (Duesterdieck-Zellmer, Driscoll \& Ott,

292 2012) for at least the last seven days of the study. This may have allowed for increased retention

293 of sGAGs, thus ameliorating earlier sGAG losses.

294 Similar to what was observed in HDT control joints in this study, aggrecan synthesis,

295 measured as CS-846 concentration in synovial fluid, has been reported to increase with repeated

296 arthrocentesis after 24 and $48 \mathrm{~h}$ in horses (Lamprecht \& Williams, 2012). This increase was

297 ameliorated in joints injected with HDT in our study, suggesting that high synovial fluid

298 concentrations of tiludronate may prevent chondrocytes anabolic response to mild insults such as

299 repeated arthrocenteses. Exercise has also been shown to increase aggrecan synthesis by

300 chondrocytes (Lamprecht \& Williams, 2012), but it is impossible to state if intraarticular injection

301 of HDT would ameliorate this response in a similar fashion.

302 Another major protein of articular cartilage matrix is collagen type II (Vachon et al.,

303 1990), and it is accepted that collagen type II degradation in cartilage is irreversible (Catterall et

304 al., 2010; Jubb \& Fell, 1980). The impact of repeat arthrocenteses on synovial fluid C2C

305 concentration appears to be variable over time in young horses (Lucia et al., 2013). After multiple 
306 arthrocenteses over a time period of $12 \mathrm{~h}$, synovial fluid C2C concentration was increased at 24

$307 \mathrm{~h}$, decreased at 7 days and unchanged at 14 days compared to baseline values. In the present 308 study, no increase in C2C was observed in LDT or HDT treated or control joints. Similarly to

309 what was reported in young horses (Lucia et al., 2013), a decrease in C2C was seen in all

310 experimental groups between $24 \mathrm{~h}$ and 14 days after treatment. Thus, changes in type II collagen

311 cleavage are likely attributable to the effect of repeat arthrocenteses, as opposed to tiludronate

312 treatment, although these results should be viewed in light of the small sample number used in 313 this study.

Synovial fluid total solids concentration increased at 24 and $48 \mathrm{~h}$ in both treated and

315 control joints of HDT horses. While this was likely due to effects from repeated arthrocenteses

316 (Francoz, Desrochers \& Latouche, 2007; Jacobsen, Thomsen \& Nanni, 2006) and saline

317 injections (Wagner, McIlwraith \& Martin, 1982) for the control joints, total solids concentration

318 increased to a much greater extent in HDT treated joints than in control joints. Thus, intraarticular

319 administration of HDT was associated with a significant increase in synovial fluid total solids

320 concentration, most likely due to increased synovial total protein concentration. Increased

321 synovial protein concentration in HDT treated joints was attributed to be most likely caused by

322 synovial inflammation, as these joints were also palpable effused 24 and $48 \mathrm{~h}$ after treatment, and

323 in clinical cases, this observation is usually associated with a synovial inflammatory response

324 (Mahaffey, 2002). However, as synovial fluid prostaglandin $\mathrm{E}_{2}$ concentration was not determined

325 in this study, we are unable to prove this assumption. It is unlikely that the high tiludronate

326 concentration in samples from HDT treated joints increased the total solids readings on the

327 refractometer, as spiking of blank synovial fluid samples with similar concentrations of

328 tiludronate did not change total solids readings (data not shown). Finally, while an increase in

329 sGAG concentration can affect total solids readings on the refractometer (data not shown), the 
330 increased total solids concentration $24 \mathrm{~h}$ after HDT treatment cannot be explained with this

331 phenomenon, as sGAG concentratin was not elevated at that time point.

332 An unexpected finding was a significant elevation of the total nucleated cell count in both,

333 HDT treated and HDT control joints 7 days after treatment. This is unlikely to be due to repeat

334 arthrocenteses, as no arthrocenteses had been performed for the previous 5 days and elevation of

335 nucleated cell counts in synovial fluid due to repeat arthrocenteses have been reported to occur

336 within $24-48 \mathrm{~h}$ after initial arthrocentesis in horses (White et al., 1989) and calves (Francoz,

337 Desrochers \& Latouche, 2007) and it has been suggested that joints can adapt to repeated

338 arthrocenteses over time, resulting in fewer alterations of total protein concentration and

339 nucleated cell counts after 24 h (Francoz, Desrochers \& Latouche, 2007; White et al., 1989).

340 Further, there was no increase in total nucleated cell count 7 days after treatment in horses treated

341 with LDT. Thus, the cause for this increase in total nucleated cell count is unclear.

Although LDT resulted in synovial tiludronate concentrations that remained within a

343 range shown to be safe and beneficial for articular cartilage in vitro, these concentrations were

344 maintained only for 24 to $48 \mathrm{~h}$, which may not be sustained enough to provide lasting beneficial

345 effects. However, it is possible that this dose is sufficient to affect subchondral bone remodeling

346 in treated joints if tiludronate diffuses through hyaline and calcified cartilage into adjacent

347 subchondral bone, although it is unknown whether or not this occurs. Investigations to determine

348 tiludronate content in subchondral bone after intraarticular administration are necessary to answer

349 this question.

350 Interestingly, tiludronate was detectable in two control joints of horses treated with HDT, 351 although concentrations were below the linear part of the standard curve for the tiludronate assay. 
352 This finding is most likely explained by absorption of tiludronate from synovial fluid by synovial 353 capillaries, followed by redistribution into peripheral tissues, including distant joints. In support

354 of this, radioactivity from technetium 99 medronate, a radioactively labeled bisphosphonate, was

355 detectable in peripheral plasma within $5 \mathrm{~min}$ after intraarticular injection, peaked at about $45 \mathrm{~min}$,

356 and was still detectable 24 h post intraarticular injection (Dulin et al., 2012). Alternatively,

357 contamination of the two samples from HDT control joints may have occurred during sample 358 processing.

The first hypothesis, that a single intraarticular injection of HDT, but not of LDT would

360 have a negative impact on variables of joint health, compared to contralateral control joints was

361 statistically confirmed in this preliminary investigation. However, the observed changes are of

362 questionable clinical significance and further investigation with a greater number of horses is

363 warranted. The second hypothesis that intraarticular injection of HDT would result in

364 histologically detectable articular cartilage damage was rejected, but the low power of this

365 preliminary study has to be taken into consideration when interpreting this result.

\section{Conclusions}

367 This study suggests that intraarticular administration of a high dose of tiludronate (50 mg)

368 may result in temporary elevation of synovial fluid total solids and sGAG concentration. Further,

369 this dose may prevent chondrocytes' short-term anabolic response to mild insults such as repeated

370 arthrocenteses. However, a high dose of tiludronate did not appear to negatively affect cartilage

371 or synovial membrane as assessed via histologic analysis 2 weeks after treatment. Thus, the

372 clinical significance of these findings remains questionable and further study of possible negative 
373 effects of a high dose of tiludronate administered intraarticularly in a larger number of horses is

374 warranted.

375 Intraarticular administration of a low dose of tiludronate $(0.017 \mathrm{mg})$ did not appear to

376 impact assessed variables of joint health, although this finding has to be interpreted with caution,

377 due to the small number of horses investigated.

\section{Acknowledgements}

379 The authors thank Drs. Stacy Semevolos and Erica McKenzie for their critical review of

380 this manuscript.

\section{References}

382 Catterall JB, Stabler TV, Flannery CR, Kraus VB. 2010. Changes in serum and synovial fluid 383

384

385

386

387

388

389

390

391

392

393

394

395

396

397

398

399

400

401

402

403

404

405

406

407

408 biomarkers after acute injury (NCT00332254). Arthritis Research \& Therapy 12:R229.

Coudry V, Thibaud D, Riccio B, Audigie F, Didierlaurent D, Denoix JM. 2007. Efficacy of tiludronate in the treatment of horses with signs of pain associated with osteoarthritic lesions of the thoracolumbar vertebral column. American Journal of Veterinary Research 68:329-337.

Davidson EJ, Orsini JA. 2008. Arthrocentesis and synovial fluid analysis. In: Orsini JA, Divers TJ, eds. Equine emergencies: Treatment and procedures. 3rd ed. St. Louis, MO: Saunders Elsevier, 272-273.

de Grauw JC, van de Lest $\mathrm{CH}$, van Weeren PR. 2009. Inflammatory mediators and cartilage biomarkers in synovial fluid after a single inflammatory insult: a longitudinal experimental study. Arthritis Research \& Therapy 11:R35.

Denoix JM, Thibaud D, Riccio B. 2003. Tiludronate as a new therapeutic agent in the treatment of navicular disease: a double-blind placebo-controlled clinical trial. Equine Veterinary Journal 35:407-413.

Drake MT, Clarke BL, Khosla S. 2008. Bisphosphonates: mechanism of action and role in clinical practice. Mayo Clinic Proceedings 83:1032-1045.

Duesterdieck-Zellmer KF, Driscoll N, Ott JF. 2012. Concentration-dependent effects of tiludronate on equine articular cartilage explants incubated with and without interleukin1beta. American Journal of Veterinary Research 73:1530-1539.

Dulin JA, Drost WT, Phelps MA, Santschi EM, Menendez MI, Bertone AL. 2012. Influence of exercise on the distribution of technetium Tc $99 \mathrm{~m}$ medronate following intra-articular injection in horses. American Journal of Veterinary Research 73:418-425.

Ekman L, Nilsson G, Persson L, Lumsden JH. 1981. Volume of the synovia in certain joint cavities in the horse. Acta Veterinaria Scandinavica 22:23-31.

EMEA. 2001. Tiludronic acid, disodium salt: Summary Report - Committee for Veterinary Medicinal Products. Reference Number: EMEA/MRL/774/01-FINAL. Available at 
http://www.ema.europa.eu/docs/en_GB/document_library/Maximum_Residue_Limits_Report/2009/11/WC500015613.pdf (accessed 27 November 2013).

Emonds-Alt X, Breliere JC, Roncucci R. 1985. Effects of 1-hydroxyethylidene-1,1 bisphosphonate and (chloro-4 phenyl) thiomethylene bisphosphonic acid (SR 41319) on the mononuclear cell factor-mediated release of neutral proteinases by articular chondrocytes and synovial cells. Biochemical Pharmacology 34:4043-4049.

Francoz D, Desrochers A, Latouche JS. 2007. Effect of repeated arthrocentesis and single joint lavage on cytologic evaluation of synovial fluid in 5 young calves. Canadian Journal of Veterinary Research 71:129-134.

Gough MR, Thibaud D, Smith RK. 2010. Tiludronate infusion in the treatment of bone spavin: a double blind placebo-controlled trial. Equine Veterinary Journal 42:381-387.

Jacobsen S, Thomsen MH, Nanni S. 2006. Concentrations of serum amyloid A in serum and synovial fluid from healthy horses and horses with joint disease. American Journal of Veterinary Research 67:1738-1742.

Jubb RW, Fell HB. 1980. The breakdown of collagen by chondrocytes. Journal of Pathology 130:159-167.

Lamprecht ED, Williams CA. 2012. Biomarkers of antioxidant status, inflammation, and cartilage metabolism are affected by acute intense exercise but not superoxide dismutase supplementation in horses. Oxid Med Cell Longev 2012:920-932.

Liljebrink Y, Bergh A. 2010. Goniometry: is it a reliable tool to monitor passive joint range of motion in horses? Equine Veterinary Journal 42(Suppl. 38):676-682.

Lucia JL, Coverdale JA, Arnold CE, Winsco KN. 2013. Influence of an intra-articular lipopolysaccharide challenge on markers of inflammation and cartilage metabolism in young horses. Journal of Animal Science 91:2693-2699.

Mahaffey EA. 2002. Synovial fluid. In: Cowell RL, Tyler RD, eds. Diagnostic cytology and hematology of the horse. 2nd ed. St. Louis, MO: Mosby, 163-170.

Mcllwraith CW. 2005. Use of synovial fluid and serum biomarkers in equine bone and joint disease: a review. Equine Veterinary Journal 37:473-482.

McIlwraith CW, Frisbie DD, Kawcak CE, Fuller CJ, Hurtig M, Cruz A. 2010. The OARSI histopathology initiative - recommendations for histological assessments of osteoarthritis in the horse. Osteoarthritis and Cartilage 18 Suppl 3:S93-105.

Nieves JW, Cosman F. 2010. Atypical subtrochanteric and femoral shaft fractures and possible association with bisphosphonates. Current Osteoporosis Reports 8:34-39.

Oke SL, Hurtig MB, Keates RA, Wright JR, Lumsden JH. 2003. Assessment of three variations of the 1,9-dimethylmethylene blue assay for measurement of sulfated glycosaminoglycan concentrations in equine synovial fluid. American Journal of Veterinary Research 64:900906.

Poole AR, Ionescu M, Swan A, Dieppe PA. 1994. Changes in cartilage metabolism in arthritis are reflected by altered serum and synovial fluid levels of the cartilage proteoglycan aggrecan. Implications for pathogenesis. Journal of Clinical Investigation 94:25-33.

Rizkalla G, Reiner A, Bogoch E, Poole AR. 1992. Studies of the articular cartilage proteoglycan aggrecan in health and osteoarthritis. Evidence for molecular heterogeneity and extensive molecular changes in disease. Journal of Clinical Investigation 90:2268-2277.

Rogers MJ, Crockett JC, Coxon FP, Monkkonen J. 2011. Biochemical and molecular mechanisms of action of bisphosphonates. Bone 49:34-41.

Ross MW. 2011. Manipulation. In: Ross MW, Dyson SJ, eds. Diagnosis and management of lameness in the horse. 2nd ed. St. Louis, MO: Elsevier Saunders, 80-88.

Tarcomnicu I, Gheorghe MC, Silvestro L, Savu SR, Boaru I, Tudoroniu A. 2009. Highthroughput HPLC-MS/MS method to determine ibandronate in human plasma for

PeerJ reviewing PDF | (v2014:02:1583:2:0:NEW 29 Jul 2014) 
458

459

460

461

462

463

464

465

466

467

468

469

470

471

472

473

474 pharmacokinetic applications. Journal of Chromatography B Analytical Technologies in the Biomedical and Life Sciences 877:3159-3168.

Vachon AM, Keeley FW, Mcllwraith CW, Chapman P. 1990. Biochemical analysis of normal articular cartilage in horses. American Journal of Veterinary Research 51:1905-1911.

van den Boom R, van de Lest CH, Bull S, Brama RA, van Weeren PR, Barneveld A. 2005. Influence of repeated arthrocentesis and exercise on synovial fluid concentrations of nitric oxide, prostaglandin E2 and glycosaminoglycans in healthy equine joints. Equine Veterinary Journal 37:250-256.

Wagner AE, McIlwraith CW, Martin GS. 1982. Effect of intra-articular injection of orgotein and saline solution on equine synovia. American Journal of Veterinary Research 43:594-597.

White KK, Hodgson DR, Hancock D, Parry BW, Cordell C. 1989. Changes in equine carpal joint synovial fluid in response to the injection of two local anesthetic agents. Cornell Veterinarian 79:25-38.

Zhu LS, Lapko VN, Lee JW, Basir YJ, Kafonek C, Olsen R, Briscoe C. 2006. A general approach for the quantitative analysis of bisphosphonates in human serum and urine by highperformance liquid chromatography/tandem mass spectrometry. Rapid Communications in Mass Spectrometry 20:3421-3426. 


\section{Table $\mathbf{1}_{\text {(on next page) }}$}

Number of horses with middle carpal joint effusion before and after intraarticular administration of saline, LDT or HDT

Table 1: Number of horses with middle carpal joint effusion before and after intraarticular administration of saline, LDT or HDT. 
1Table 1: Number of horses with middle carpal joint effusion before and after intraarticular 2administration of saline, LDT or HDT.

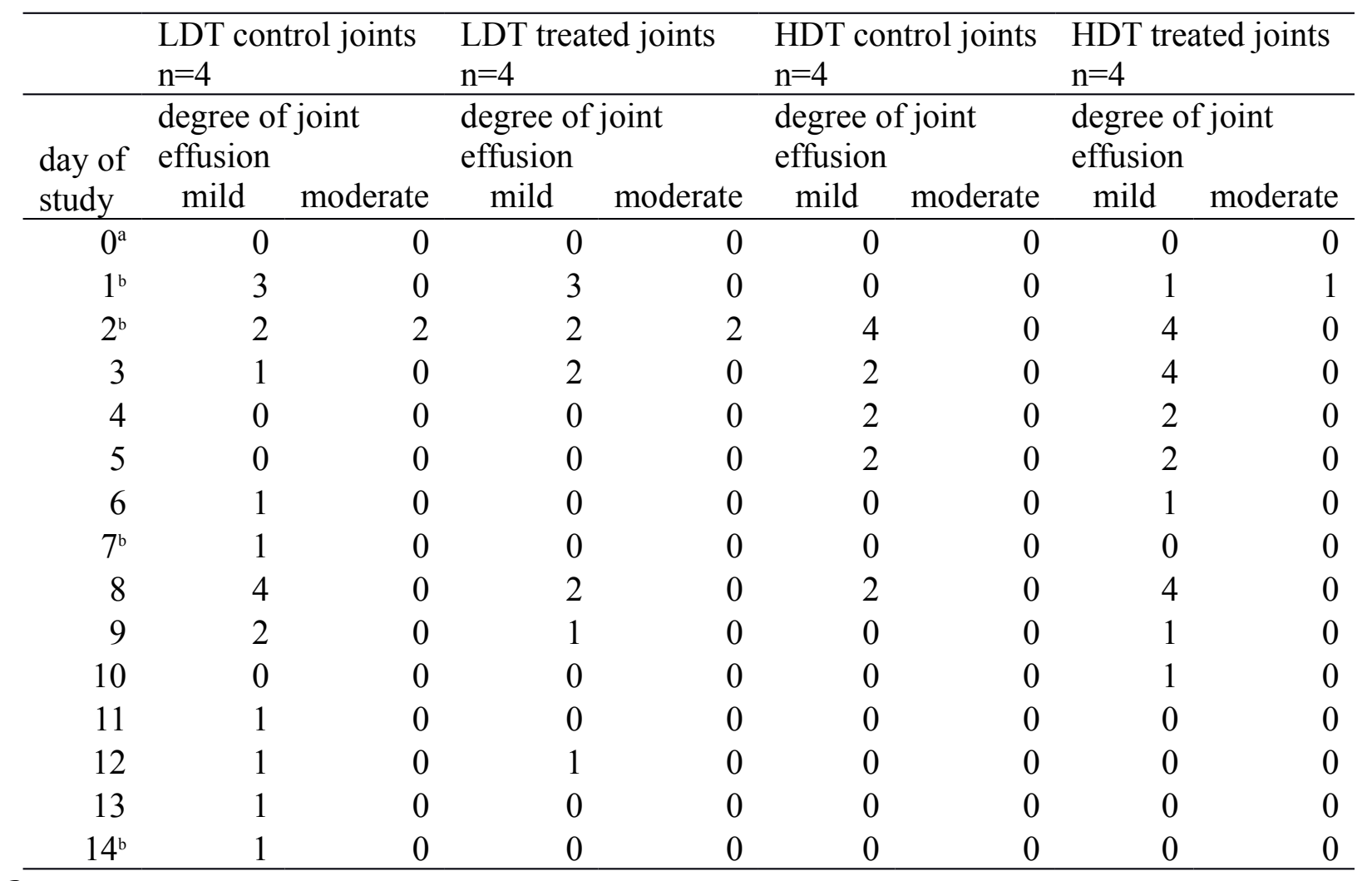

3

4Notes.

$5^{\mathrm{a} O b s e r v a t i o n s ~ w e r e ~ m a d e ~ p r i o r ~ t o ~ a n y ~ i n t r a a r t i c u l a r ~ i n j e c t i o n s ~ o r ~ a r t h r o c e n t e s e s . ~}$

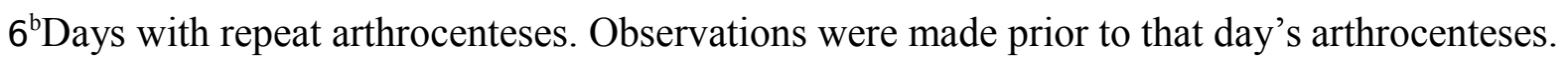




\section{Table 2 (on next page)}

Median joint angle of maximum flexion and total range in horses treated with either LDT or HDT in one middle carpal joint and with saline in the contralateral joint.

Table 2: Median joint angle of maximum flexion and total range in horses treated with either LDT or HDT in one middle carpal joint and with saline in the contralateral joint. 
1Table 2: Median joint angle of maximum flexion and total range in horses treated with either 2LDT or HDT in one middle carpal joint and with saline in the contralateral joint.

\begin{tabular}{|c|c|c|c|c|c|c|c|c|}
\hline $\begin{array}{l}\text { day of } \\
\text { study }\end{array}$ & $\begin{array}{l}\text { LDT con } \\
\text { median }\end{array}$ & $\begin{array}{l}\text { joints } \\
\text { total } \\
\text { range }\end{array}$ & $\begin{array}{l}\text { LDT trea } \\
\text { median }\end{array}$ & $\begin{array}{l}\text { d joints } \\
\text { total } \\
\text { range }\end{array}$ & $\begin{array}{l}\text { HDT con } \\
\text { median }\end{array}$ & $\begin{array}{l}\text { ol joints } \\
\text { total } \\
\text { range }\end{array}$ & $\begin{array}{l}\text { HDT trea } \\
\text { median }\end{array}$ & $\begin{array}{l}\text { ed joints } \\
\text { total } \\
\text { range }\end{array}$ \\
\hline $0^{\mathrm{a}}$ & 11 & 6 & 13 & 8 & 4 & 6 & 3.5 & 3 \\
\hline $1^{b}$ & $8.5^{*}$ & 3 & $9^{*}$ & 4 & 3 & 2 & 4.5 & 6 \\
\hline $2^{b}$ & 10.5 & 6 & $8^{*}$ & 4 & 2.5 & 3 & 2 & 1 \\
\hline 3 & $6.5^{*}$ & 2 & $7 *$ & 6 & $2 *$ & 1 & 2 & 2 \\
\hline 4 & $9 *$ & 4 & $7.5^{*}$ & 3 & $2 *$ & 2 & $2 *$ & 2 \\
\hline 5 & $8^{*}$ & 1 & $8^{*}$ & 3 & $2^{*}$ & 1 & 2 & 1 \\
\hline 6 & $8^{*}$ & 7 & $8^{*}$ & 5 & $1 *$ & 2 & $1^{*}$ & 3 \\
\hline $7^{b}$ & 11 & 6 & 11 & 3 & $2 *$ & 4 & 2.5 & 6 \\
\hline 8 & 14 & 7 & 12.5 & 3 & $2 *$ & 1 & 2.5 & 3 \\
\hline 9 & 11.5 & 3 & 10 & 4 & $0^{*}$ & 2 & 2 & 3 \\
\hline 10 & 11.5 & 3 & 12 & 6 & $0.5^{*}+$ & 2 & $3 t$ & 3 \\
\hline 11 & 11.5 & 4 & 11.5 & 2 & $2^{*}$ & 3 & 2 & c \\
\hline 12 & 9 & 6 & $9^{*}$ & 4 & $1 *$ & 2 & 1.5 & 3 \\
\hline 13 & $7 *$ & 3 & $7^{*}$ & 2 & $2 * t$ & 2 & $3.5 t$ & 3 \\
\hline $14^{\mathrm{b}}$ & $8 *$ & 4 & $9 *$ & 2 & $0.5^{*}$ & 2 & $1 *$ & 2 \\
\hline
\end{tabular}

3

4Notes.

$5^{\mathrm{a}}$ Measurements were taken prior to any intraarticular injections or arthrocenteses.

$6^{\mathrm{b}}$ Days with repeat arthrocenteses. Measurements were taken prior to that day's arthrocenteses.

$7 *$ Significantly different from baseline measurement on day $0\left({ }^{*} P<0.05\right)$. However,

8differences in angulation of $<10^{\circ}$ are unlikely to be clinically significant (Liljebrink \& Bergh, 92010).

$10 \ddagger$ Significant difference between HDT treated and control joints $(\$ P<0.022)$. However, 11differences in angulation of $<10^{\circ}$ are unlikely to be clinically significant (Liljebrink \& Bergh, 122010). 


\section{Table 3 (on next page)}

Median histologic scores of articular cartilage and synovial membrane 14 days after intraarticular injection of $50 \mathrm{mg}$ tiludronate or saline

Table 3: Median histologic scores of articular cartilage and synovial membrane 14 days after intraarticular injection of $50 \mathrm{mg}$ tiludronate or saline. 
1 Table 3: Median histologic scores of articular cartilage and synovial membrane 14 2days after intraarticular injection of $50 \mathrm{mg}$ tiludronate or saline.

\begin{tabular}{llccc}
\hline Histologic variable & Treatment & Median score & Range & $P$-value \\
\hline Chondrocyte necrosis & tiludronate & 0 & 0 & \multirow{2}{*}{ N/A } \\
& saline & 0 & 0 & \\
Cluster formation & tiludronate & 1 & 1 & $>0.999$ \\
& saline & 1 & 1 & \\
Fibrillation/ fissuring & tiludronate & 0.5 & 1 & \multirow{2}{*}{$>0.999$} \\
& saline & 1 & 1 & \\
Focal chondrocyte loss & tiludronate & 0 & 0 & N/A \\
& saline & 0 & 0 & \\
Cartilage toluidine blue stain uptake & tiludronate & 1.5 & 1 & \\
& saline & 1 & 2 & \\
Synovial cellular infiltration & tiludronate & 1 & 2 & \multirow{2}{*}{0.25} \\
(lymphocytes and plasma cells) & saline & 0 & 1 & \\
Synovial intimal hyperplasia & tiludronate & 0.5 & 1 & $>0.999$ \\
& saline & 0.5 & 1 &
\end{tabular}

3Notes.

$4^{\mathrm{a} H i s t o l o g y}$ was scored on a scale of $0-4$, with 0 representing normal histology (McIlwraith et 5al., 2010). 


\section{Figure 1}

Graph of synovial fluid tiludronate concentration over time.

Fig. 1: Semi-log bar graph of mean synovial fluid tiludronate concentration over time.

Tiludronate was injected at a dose of $0.017 \mathrm{mg}$ in $1 \mathrm{ml}$ saline (A) or at a dose of $50 \mathrm{mg}$ in 6 $\mathrm{ml}$ saline (B) into normal middle carpal joints of 4 horses, respectively. The contralateral joints were injected with an equal volume of saline to serve as control joints. Tiludronate concentratin was determined using HPLC followed by mass spectrometry. Error bars show $+95 \%$ confidence interval of measurements from 4 horses.






\section{Figure 2}

Box-and-whisker plot of synovial fluid total solids concentration over time.

Fig. 2: Box-and-whisker plot of synovial fluid total solids concentration over time. Tiludronate was injected at a dose of $0.017 \mathrm{mg}$ in $1 \mathrm{ml}$ saline (A) or at a dose of $50 \mathrm{mg}$ in $6 \mathrm{ml}$ saline (B) into normal middle carpal joints of 4 horses, respectively. The contralateral joints were injected with an equal volume of saline to serve as control joints. Total solids concentration was determined via refractometry. The dotted horizontal line represents the upper limit of the normal reference interval (Davidson and Orsini, 2007).Whiskers represent the minimum and maximum values. Asterisks indicate significant difference compared to pre-treatment measurements in the same joints $\left({ }^{*} P<0.05\right)$. The superscript "a" indicates significant difference between treated and control joints $(\mathrm{P}<0.05)$. 
A

$0.017 \mathrm{mg}$ tiludronate IA

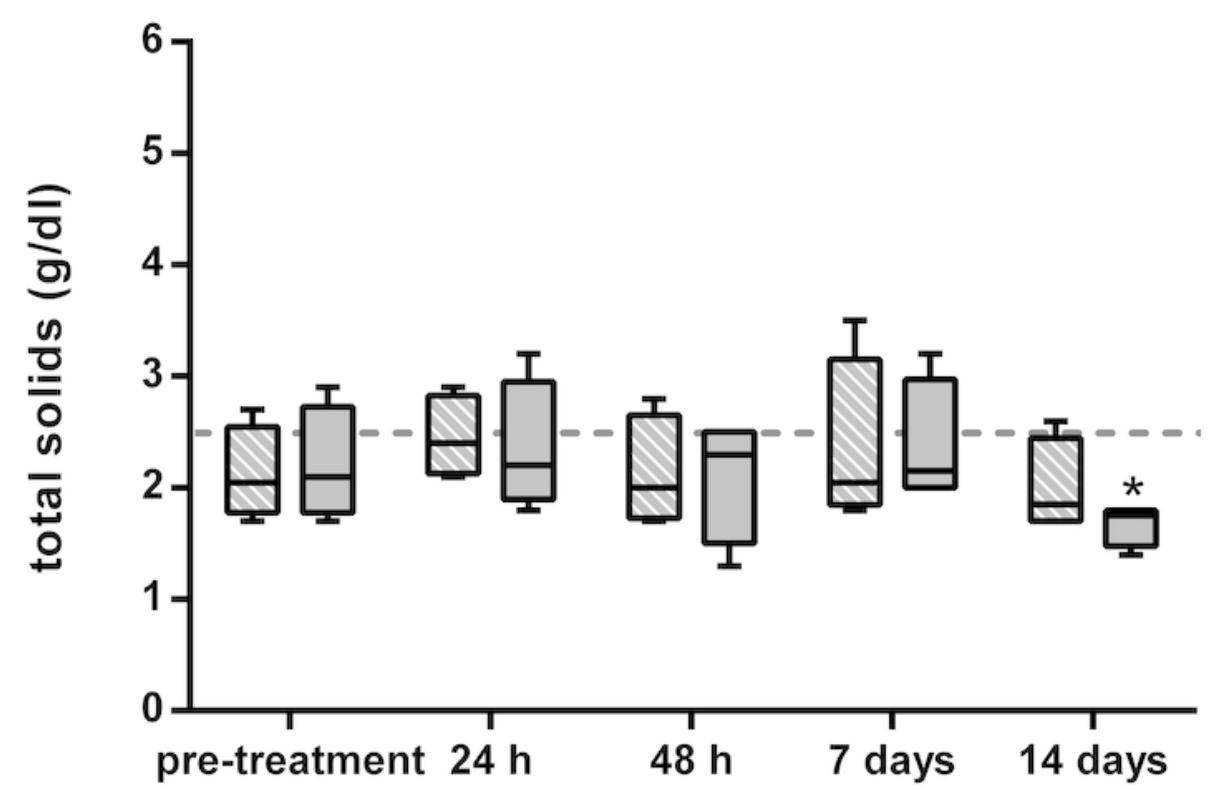

$\square$ saline

$\square$ tiludronate

B $50 \mathrm{mg}$ tiludronate IA

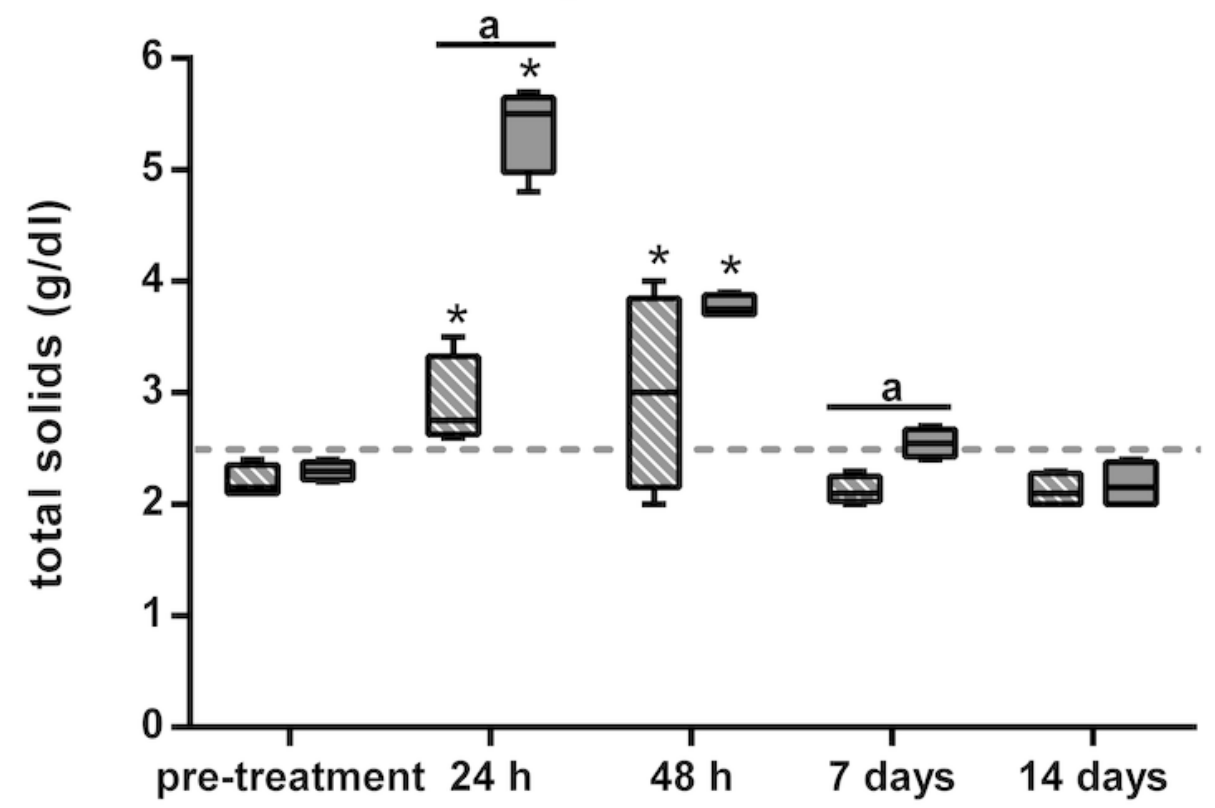

av saline

$\square$ tiludronate 


\section{Figure 3}

Box-and-whisker plot of synovial fluid sulfated glycosaminoglycan (sGAG) concentration over time

Fig. 3: Box-and-whisker plot of synovial fluid sulfated glycosaminoglycan (sGAG) concentration over time. Tiludronate was injected at a dose of $0.017 \mathrm{mg} \mathrm{in} 1 \mathrm{ml}$ saline (A) or at a dose of $50 \mathrm{mg}$ in $6 \mathrm{ml}$ saline (B) into normal middle carpal joints of 4 horses, respectively. The contralateral joints were injected with an equal volume of saline to serve as control joints. Sulfated glycosaminoglycans were quantitated using the 1,9-dimethylmethylene blue (DMMB) assay. Whiskers represent the minimum and maximum values. Asterisks indicate significant difference compared to pre-treatment measurements in the same joints $\left({ }^{*} \mathrm{P}<0.05\right)$. The superscript "a" indicates significant difference between treated and control joints $(P<0.05)$. 
A $\quad 0.017 \mathrm{mg}$ tiludronate IA

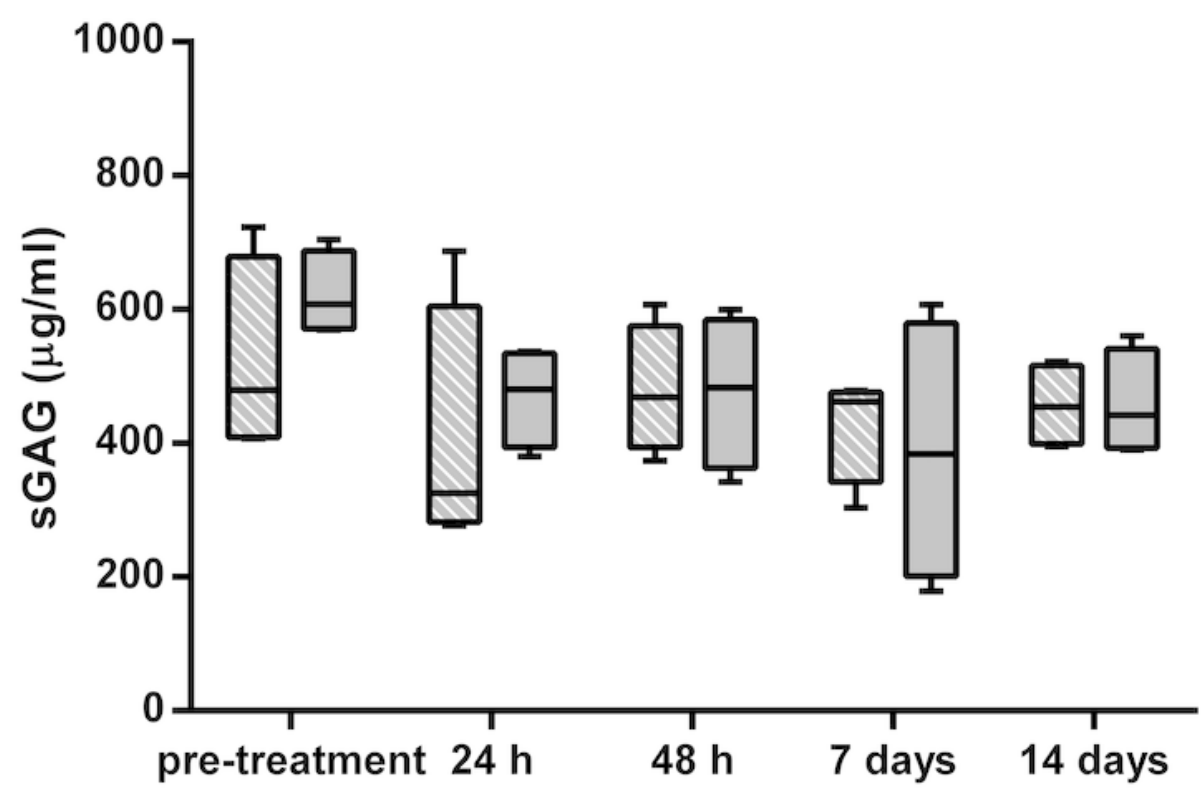

B

$50 \mathrm{mg}$ tiludronate IA

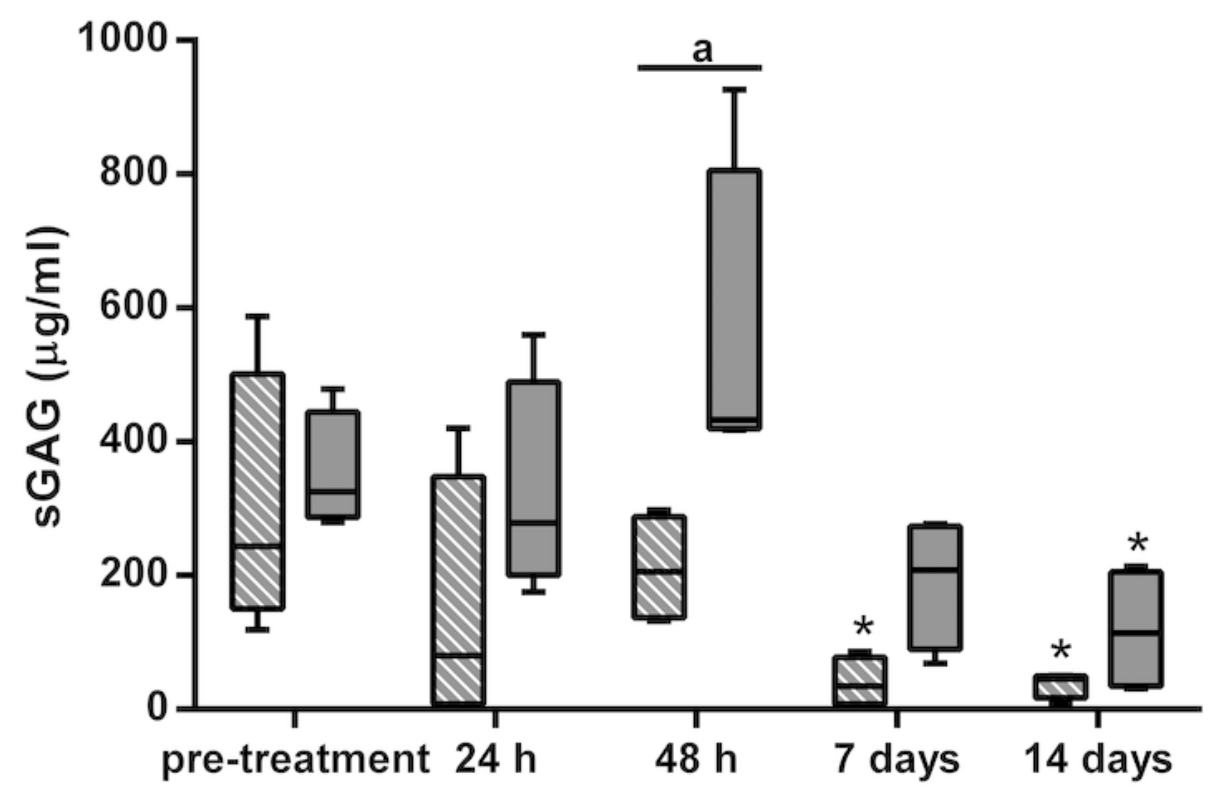

प1य saline

$\square$ tiludronate 


\section{Figure 4}

Box-and-whisker plot of synovial fluid concentration of chondroitin sulfate 846 epitope (CS-846) over time

Fig. 4: Box-and-whisker plot of synovial fluid concentration of chondroitin sulfate 846 epitope (CS-846) over time. Tiludronate was injected at a dose of $0.017 \mathrm{mg}$ in $1 \mathrm{ml}$ saline (A) or at a dose of $50 \mathrm{mg}$ in $6 \mathrm{ml}$ saline (B) into normal middle carpal joints of 4 horses, respectively. The contralateral joints were injected with an equal volume of saline to serve as control joints. Chondroitin sulfate 846 epitope was quantitated using ELISA to estimate aggrecan synthesis. Whiskers represent the minimum and maximum values. Asterisks indicate significant difference compared to pre-treatment measurements in the same joints $\left({ }^{*} \mathrm{P}<0.05\right)$. The superscript "a" indicates significant difference between treated and control joints $(P<0.05)$. 

A
$0.017 \mathrm{mg}$ tiludronate IA

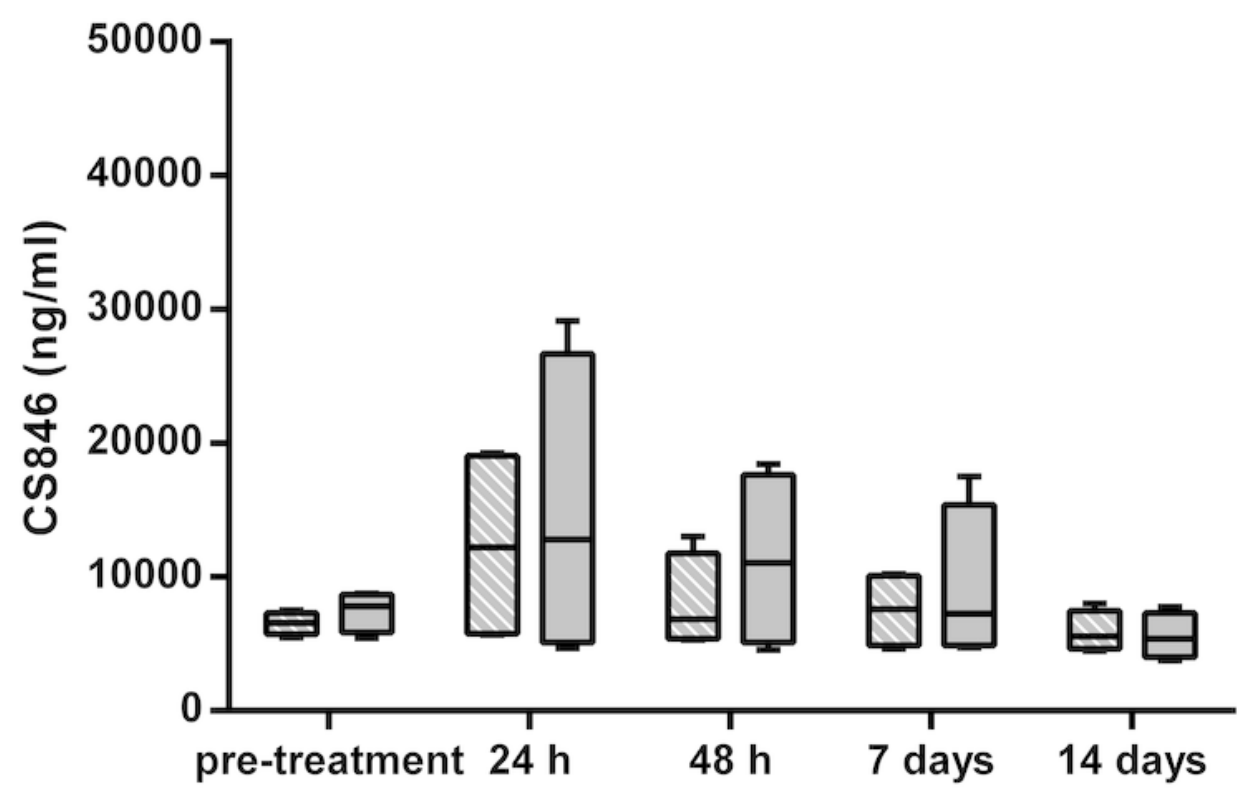

$\square$ saline

$\square$ tiludronate
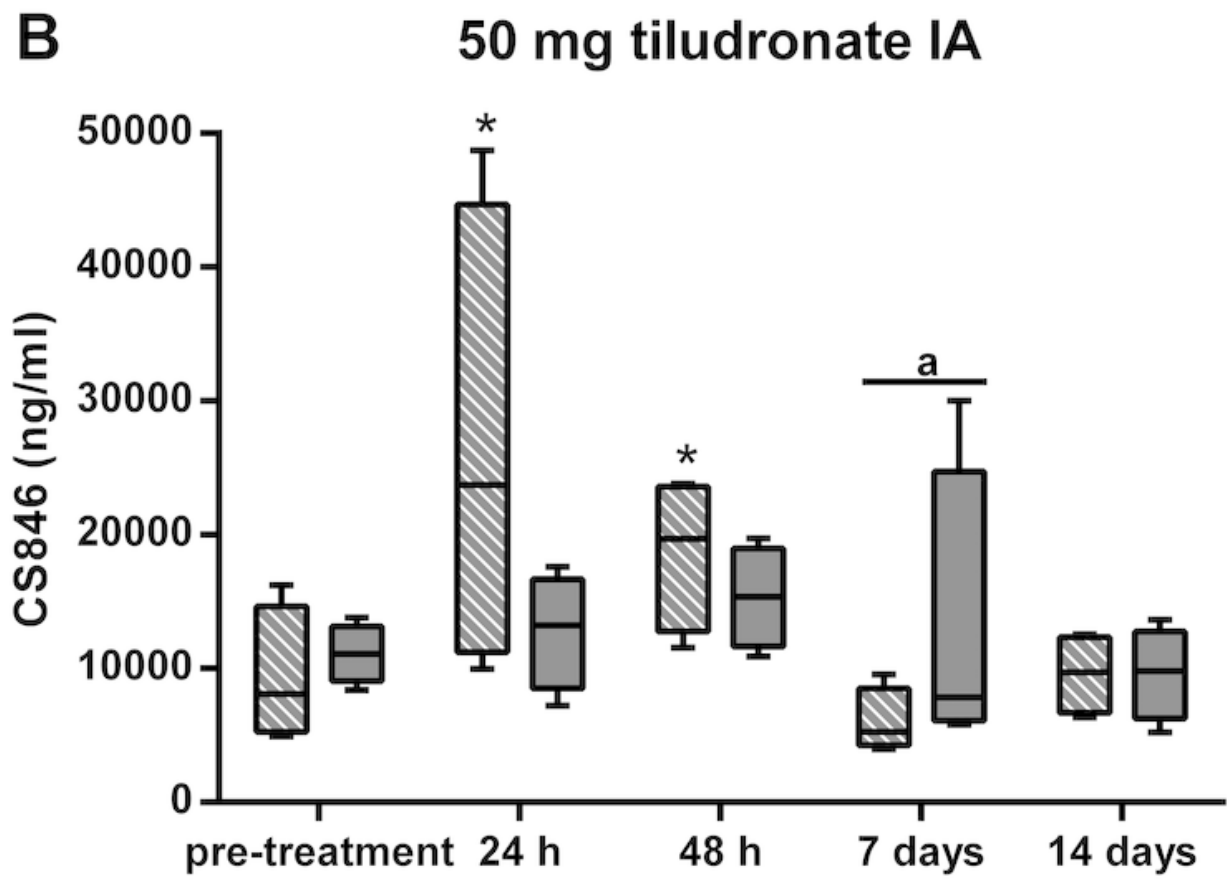

NIV saline

$\square$ tiludronate 


\section{Figure 5}

Box-and-whisker plot of synovial fluid concentration of collagen type II cleavage neoepitope (C2C) over time 
A

$0.017 \mathrm{mg}$ tiludronate IA

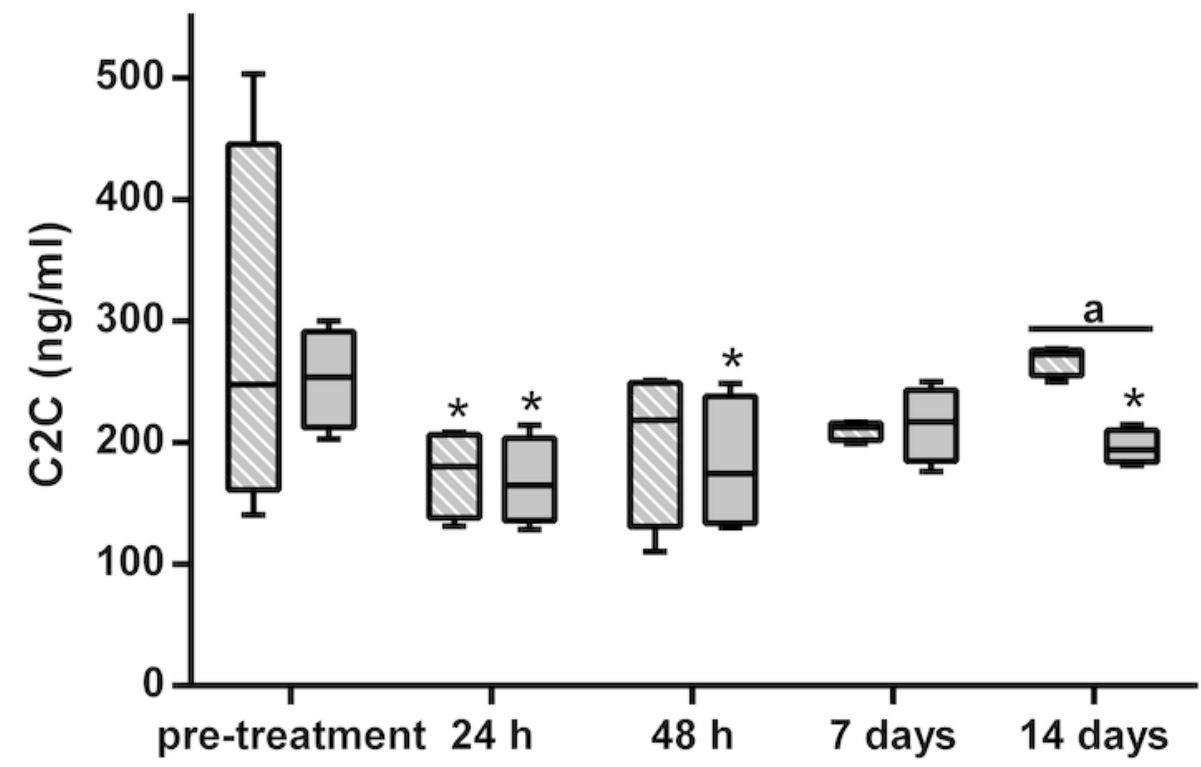

B

$50 \mathrm{mg}$ tiludronate IA

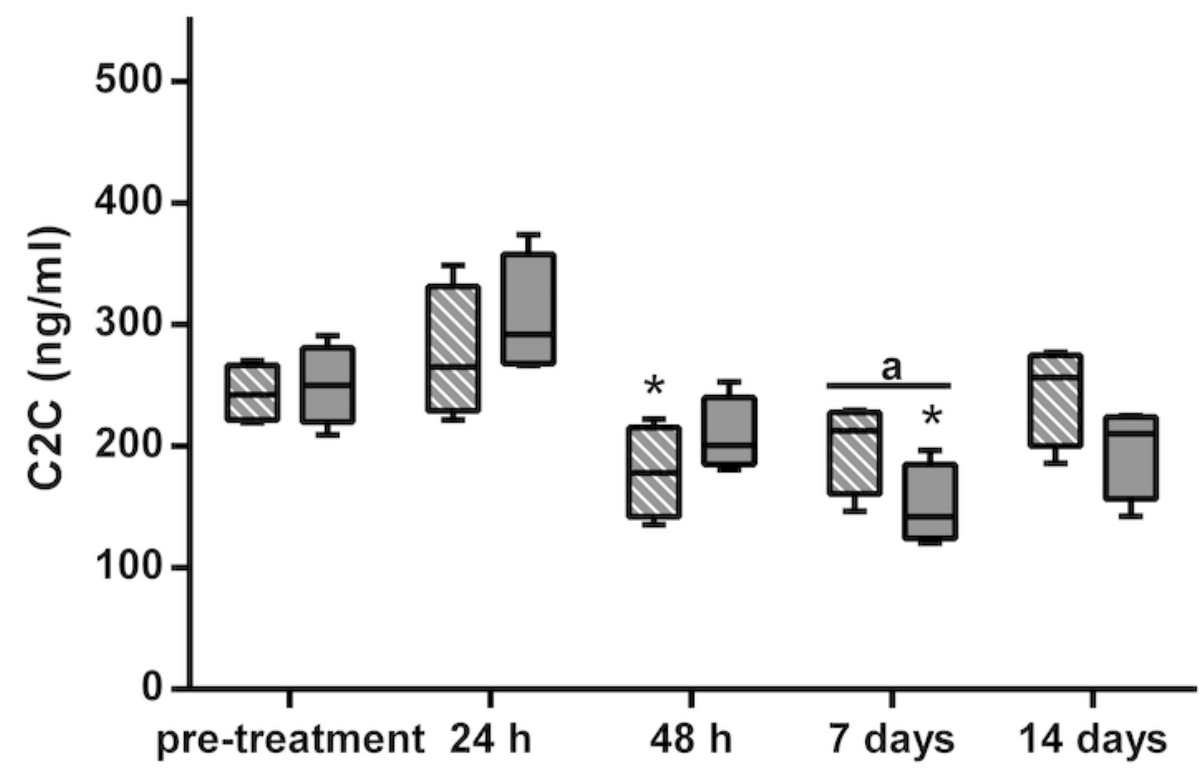

av saline

$\square$ tiludronate 